\title{
Erratum
}

\section{Erratum to "Does Urinary Bladder Shape Affect Urinary Flow Rate in Men with Lower Urinary Tract Symptoms?"}

\author{
Yusuf Ziya Ateşçi, ${ }^{1}$ Özgü Aydoğdu, ${ }^{1}$ Ayhan Karaköse, ${ }^{1}$ Mahmut Pekedis, ${ }^{2}$ Ömer Karal, ${ }^{3}$ \\ Utku Şentürk, ${ }^{2}$ and Murat Çınar ${ }^{4}$ \\ ${ }^{1}$ Department of Urology, Faculty of Medicine, Izmir University, Karsiyaka, 35200 Izmir, Turkey \\ ${ }^{2}$ Department of Mechanical Engineering, Faculty of Engineering, Ege University, Bornova, 35040 Izmir, Turkey \\ ${ }^{3}$ Department of Electrics and Electronics Engineering, Faculty of Engineering and Natural Sciences, Yildırım Beyazıt University, \\ 06050 Ankara, Turkey \\ ${ }^{4}$ Department of Biomedical Engineering, Faculty of Engineering and Architecture, Izmir Katip Celebi University, 35620 Izmir, Turkey \\ Correspondence should be addressed to Özgü Aydoğdu; ozgucan@yahoo.com
}

Received 3 February 2014; Accepted 19 February 2014; Published 18 March 2014

Copyright ( 2014 Yusuf Ziya Ateşçi et al. This is an open access article distributed under the Creative Commons Attribution License, which permits unrestricted use, distribution, and reproduction in any medium, provided the original work is properly cited.

In the paper titled "Does Urinary Bladder Shape Affect Urinary Flow Rate in Men with Lower Urinary Tract Symptoms?" we should add an author who has contributed to our study for the images: Murat Çınar, Department of Biomedical Engineering, Faculty of Engineering and Architecture, Izmir Katip Celebi University, 35620 Izmir, Turkey.

In addition we should here correct the affiliation of one of the authors named Ömer Karal and the postal code in the affiliation of the author Mahmut Pekedis. 


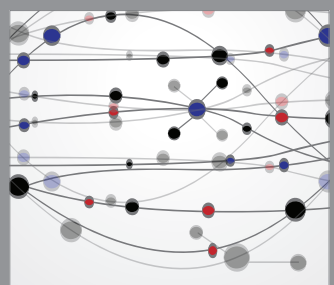

The Scientific World Journal
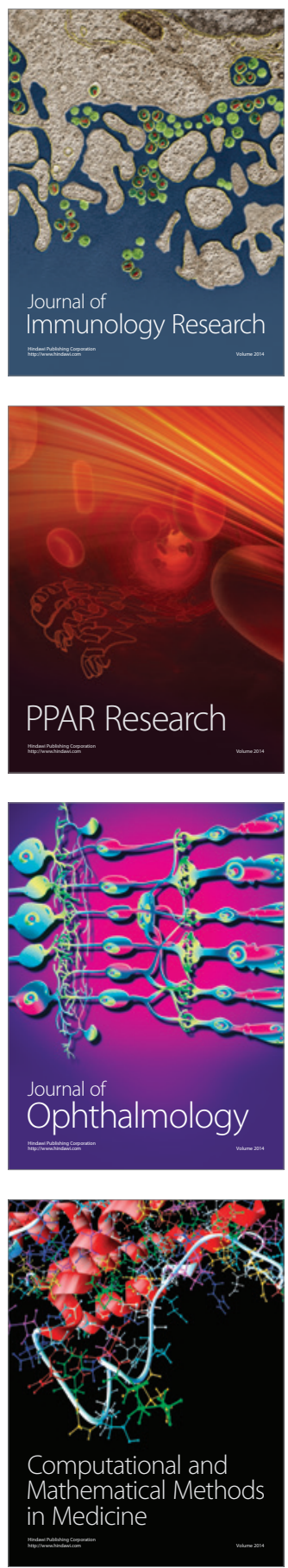

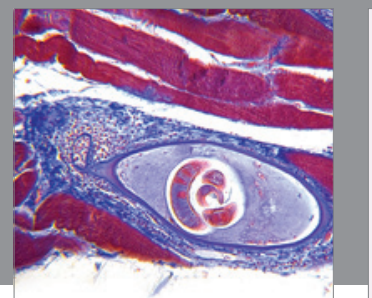

Gastroenterology

Research and Practice
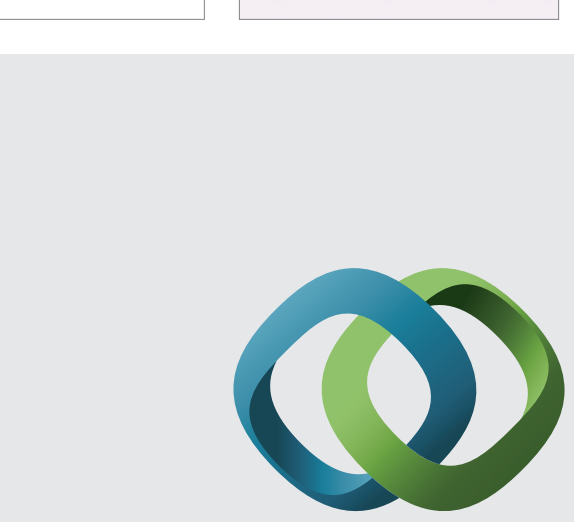

\section{Hindawi}

Submit your manuscripts at

http://www.hindawi.com
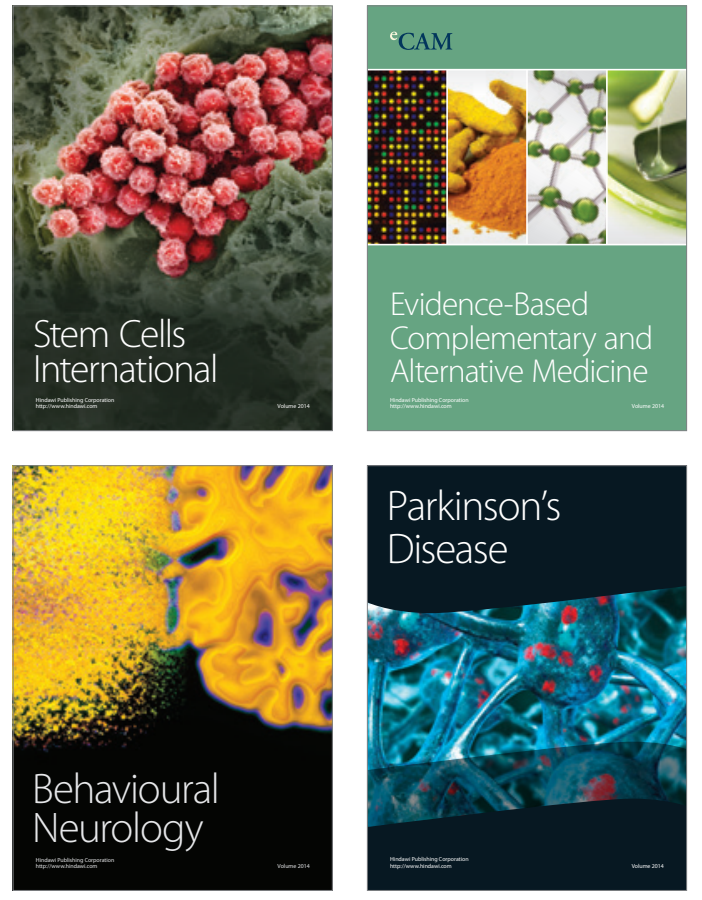
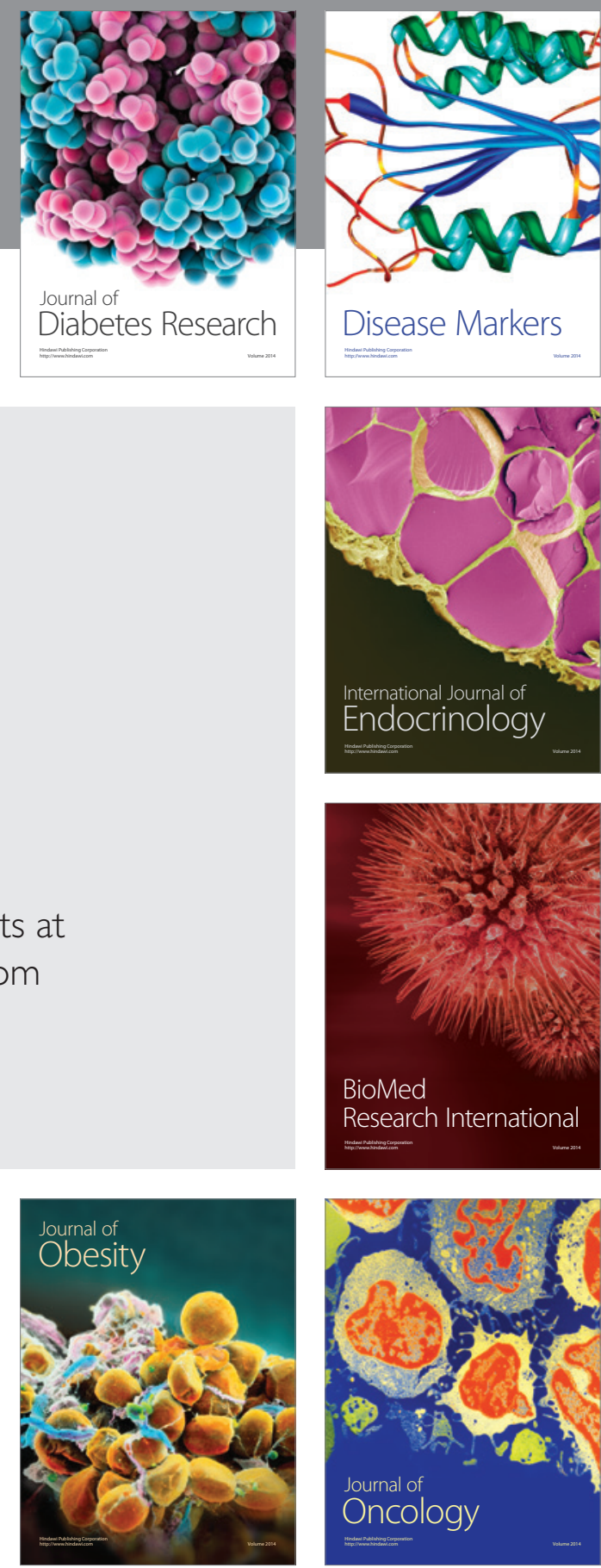

Disease Markers
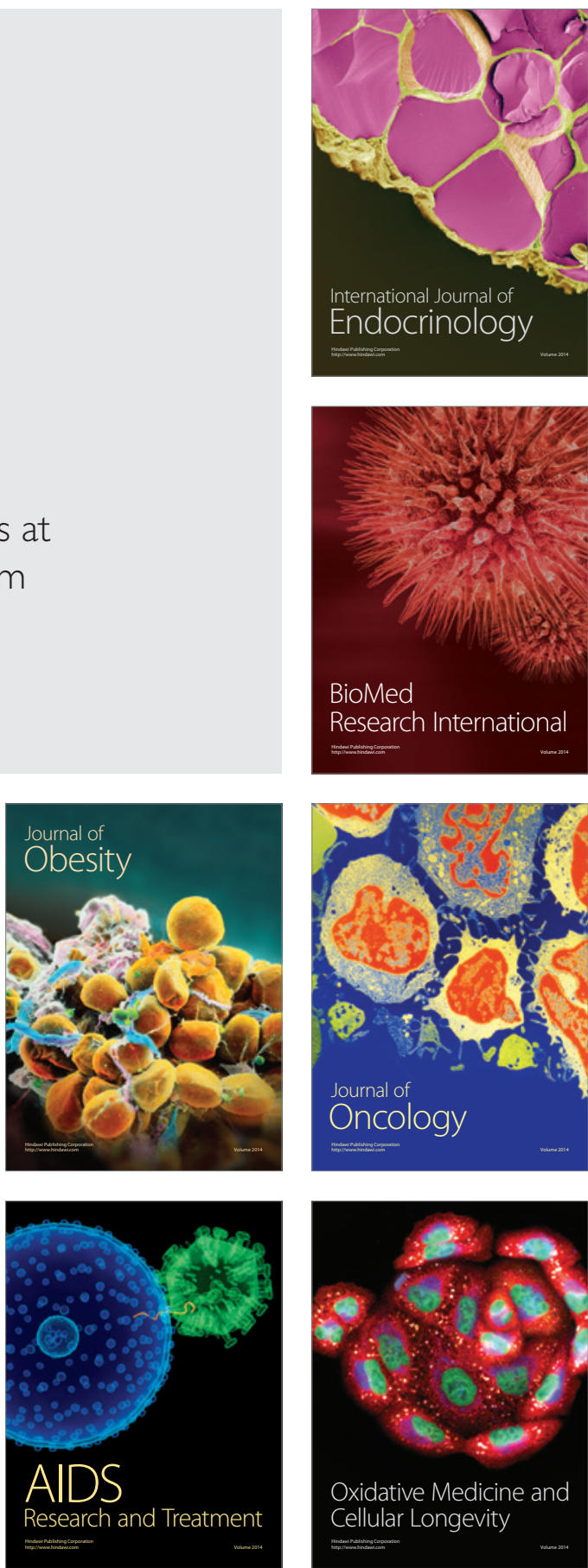